\title{
A note on the reliability of subjective judgment in discerning when the mouth is clear of salt taste stimuli
}

\author{
M. O'MAHONY \\ University of Bristol, Bristol, England
}

\begin{abstract}
The ability of Ss to judge by taste when they had expectorated exogenous $\mathrm{NaCl}$ from the mouth was tested using 10 Ss. It was found that, after a 1-M salt mouthrinse, Ss judged its taste to have vanished while there were still residuals remaining in the mouth, which would have been detected by taste at preexperimental adaptation levels. This means that Ss are unable to judge for themselves when the mouth is clear of exogenous stimuli and that intertrial procedures requiring $S s$ to do this are suspect.
\end{abstract}

Dallenbach and Dallenbach (1943) showed that taste adaptation can be so strong that a sensation completely disappears after a certain presentation time. McBurney and Pfaffmann (1963) showed that despite its appreciable $\mathrm{NaCl}$ concentration, the taste of saliva is not perceived because of adaptation by the taste receptors. Békésy (1960), using a semiautomatic gustometer, demonstrated that adaptation near the threshold can be so strong that a constant shift of threshold occurs. Further work has been done on the psychophysical (McBurney, Kasschau, \& Bogart, 1967) and qualitative (Bartoshuk, McBumey, \& Pfaffmann, 1964: Bartoshuk, 1968) effects of adaptation to $\mathrm{NaCl}$ as well as extensive cross-adaptation studies (Meiselman, 1968a, b; McBurney \& Lucas, 1966; Smith \& McBurney, 1969), including effects on the taste of water (McBurney \& Shick, 1971: O'Mahony, 1972c).

Possible sensitivity changes due to adaptation tend to be ignored during most psychophysical experiments. One possible factor that can affect the level of adaptation of the taste receptors is the quantity of any residual stimulus that remains in the saliva from prior tastings and which may not have been completely expectorated. The amount of residual would depend on the thoroughness of the interstimulus procedure used during the study.

There is no general agreement on interstimulus rest procedures and their effect on taste acuity: there are a wide variety of procedures in use, none of which have the necessary research to support them. O'Mahony $(1972 a, b)$ has shown that interstimulus procedures that use a fixed time interval or number of mouth rinses are generally insufficient to remove significant $\mathrm{NaCl}$ residuals from prior tastings. Other workers favor, rather than an interstimulus procedure fixed by the $E$, a procedure which allows Ss to judge for themselves when the mouth is clear of residuals from prior tastings.

Richter and MacLean (1939) allowed Ss to proceed in successive tastings as rapidly as they desired, while Williams (1970) reported interstimulus intervals to be anywhere from $20 \mathrm{sec}$ to $2 \mathrm{~min}$. Gregson (1966) used an ad lib mouth-rinsing procedure with deionized water between tastings, allowing the $S$ to judge the number of rinses required. Other studies merely stated that water mouthrinses were used (Knowles \& Johnson, 1941; U.S. Department of Agriculture, 1943), and it must be assumed that the Ss judged for themselves when the mouth was clear of residuals. Brown (1914), however, admitted that to allow his Ss to use their own discretion as to when they had had sufficient mouth rinses was to be thoughtlessly following precedent. Cameron (1947) was even more lax: he recommended that not only the number of rinses but also whether to use them at all should be left to the discretion of the $\mathrm{S}$.

Any method that allows a $S$ to judge for himself when the mouth has been cleared of taste stimuli remains suspect because of sensitivity changes with adaptation. It is expected that taste receptors will adapt to stimuli in the mouth and hence not be able to detect small residual stimulus quantities remaining in the mouth after expectoration. This being so, it may be asked whether or not such undetectable amounts of residual are important, as they most certainly are for fixed time intervals (O'Mahony, 1972b). The present study investigates the amount of undetectable $\mathrm{NaCl}$ residual remaining after expectoration of a $1-\mathrm{M} \mathrm{NaCl}$ mouthrinse.

\section{METHOD}

\section{Procedure}

The Ss were required to judge when, after expectorating a $1-\mathrm{M}$ $\mathrm{NaCl}$ mouthrinse, they could no longer perceive a salty taste in the mouth. No more precise psychophysical procedure than a simple judgment was used, because this is the condition for actual psychophysical experiments. A $1-\mathrm{M} \mathrm{NaCl}$ solution was. used because it is a concentration commonly used in intensity scaling experiments where residuals are likely to be high, and also because the error in the measured longer "recovery times" will be reduced accordingly. Also, confusions due to language (O'Mahony, 1973; O'Mahony \& Godman, 1973a, b) will be less important than if near-threshold solutions were used.

Four male and six female Ss, staff and students of Bristol University, aged 18-35 years, were used. They were seated comfortably and required to expectorate at 2 -min intervals into $100-\mathrm{ml}$ beakers. After collection of four samples of saliva, $15 \mathrm{ml}$ of $1-\mathrm{M} \mathrm{NaCl}$ were sipped, swilled round the mouth for $15 \mathrm{sec}$. and expectorated; $S$ s then continued to expectorate at 15 -sec intervals for $30 \mathrm{~min}$. The $S$ was instructed to inform the $E$ as soon as he judged that the salty taste had vanished, during the 
Table 1

Concentrations of $\mathrm{NaCl}$ in Saliva Before Rinsing With $1 \mathrm{M} \mathrm{NaCl}$ and at the Time of Subjective Report That Taste Had Vanished

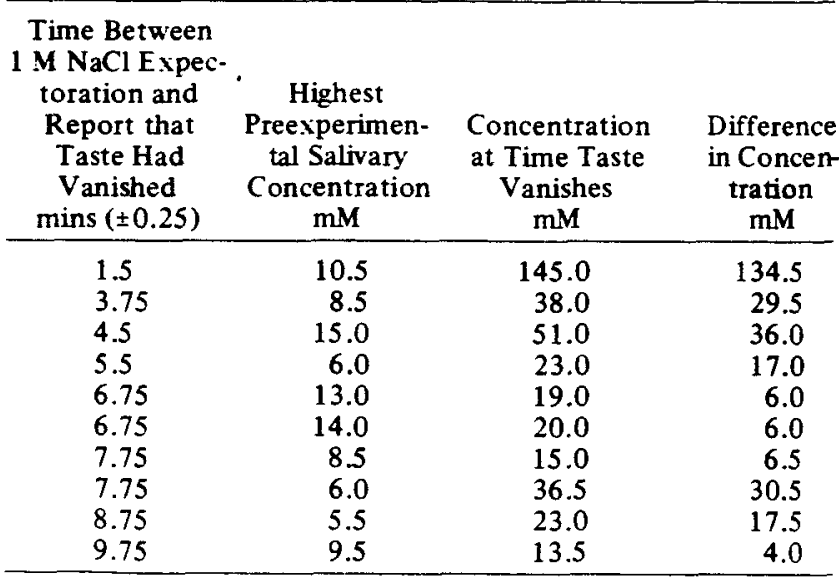

$30-\mathrm{min}$ period. The expectorations, made at 2 -min intervals, were collected and analyzed for $\mathrm{Na}$ by flame photometry, using a L'nicam SP-90 spectrometer. Curves were constructed, plotting concentration against time, enabling interpolation of the $\mathrm{Na}$ concentration at the timie that the $\mathrm{S}$ stated that the salt taste had vanished.

\section{RESULTS AND DISCUSSION}

Table 1 shows the times, after expectoration of the 1-M NaCl solution, that Ss first stated that the salt taste had vanished. It can be seen that all Ss reported that the taste had vanished within $10 \mathrm{~min}$ of expectoration of the $1-\mathrm{M} \mathrm{NaCl}$ solution; this agrees with previous research by O'Mahony (1972a). Surprisingly, only one S reported that the taste had vanished within $2 \mathrm{~min}$, which is the longest commonly used rest. period for such concentrations (Meiselman, 1971).

From Table 1 it can also be seen that at the time that Ss reported the salt taste to have vanished, the $\mathrm{Na}$ content of saliva was higher than preexperimental levels for all Ss. Given this concentration difference, its importance has to be assessed. One way of doing this is to see whether the differences would be detectable by taste or, more precisely, whether $\mathrm{NaCl}$ concentrations, at the time that Ss reported the taste to have vanished, could be detected by taste with adaptation levels equal to preexperimental salivary $\mathrm{Na}$ levels. This question could not be answered by in situ threshold measures because of interference due to sensitivity drifts. However, using flow procedures to hold a constant adaptation level, McBurney and Pfaffmann's (1963) and O'Mahony's (in press, a) results indicate that a $\mathrm{NaCl}$ stimulus of concentration $5 \mathrm{mM}$ greater than the level of adaptation is readily detected. For all but one of the Ss, the difference between the preexperimental and "taste vanishing" salivary concentrations was greater than $5 \mathrm{mM}$ and would thus be detected. The exception (4 mM) may well be detected also. Most concentration differences were, in fact, over three times greater than $5 \mathrm{mM}$.
This is strong evidence that, by the time Ss judged the taste to have vanished, their level of adaptation had risen above preexperimental levels by an amount that could be readily detected by taste. Thus, Ss were unable to judge by taste when an exogenous $\mathrm{NaCl}$ stimulus had been expelled from the oral environment, and any interstimulus procedure requiring them to do this would suffer accordingly.

The best way to avoid the problem of residuals from prior tastings or having Ss judge when they have been expectorated is to avoid in situ tasting altogether and use a flow apparatus (Anderson et al, 1971; O'Mahony, in press, b). This causes saliva to be washed from the taste receptors and to be replaced by a solution of known concentration, thus fixing the level of adaptation. Such a technique is not suitable for food assessment, however, where perhaps an internal comparison procedure between blocks of trials may monitor any sensitivity drifts which may then be allowed for.

Because the effects discussed here are due to $\mathrm{NaCl}$ residuals from prior tastings, there is every reason to expect that it is a general effect for all stimuli that are soluble enough to remain in the saliva in large concentrations. This applies to most taste stimuli.

\section{REFERENCES}

Andersson, I.. Hellekant, G., Larsson, R., Molander, C., \& Ström, L. A system for manually or automatically controlled gustatory stimulation. Medical \& Biological Engineering, $1971,9,715-717$.

Bartoshuk, L. M. Water taste in man. Perception \& Psychophysics, 1968, 3, 69-72.

Bartoshuk, L. M., McBurney, D. H., \& Pfaffmann, C. Taste of sodium chloride solutions after adaptation to sodium chloride: Implications for the "water taste." Science, 1964, 143, 967-968.

Békésy, G. von. The effect of adaptation on the taste threshold observed with a semiautomatic gustometer. Journal of General Physiology, 1960, 48, 481-488.

Brown, W. The judgement of very weak sensory stimuli with special reference to absolute threshold of sensation for common salt. University of California Publications in Psychology, 1914, 1, 199-286.

Cameron, A. T. The taste sense and the relative sweetness of sugars and other sweet substances. Scientific Reports of the Sugar Research Foundation, 1947, No. 9, 1-71.

Dallenbach, J. W., \& Dallenbach, K. M. The effects of bitter adaptation on sensitivity to the other taste qualities. American Journal of Psychology, 1943, 56, 21-31.

Gregson, R. A. M. Qualitative identification of the taste of weak sucrose-sodium chloride mixture stimuli. Perception \& Psychophysics, 1966, 1, 154-156.

Knowles, D., \& Johnson, P. E. A study on the sensitiveness of prospective food judges to the primary tastes. Food Research, $1941,6,207-216$.

McBumey, D. H., Kasschau, R. A., \& Bogart, L. M. The effect of adaptation on taste jnds. Perception \& Psychophysics, 1967, 2, 175-178.

McBurney, D. H., \& Lucas, L. A. Gustatory cross adaptation between salts. Psychonomic Science, 1966, 4, 301-302.

McBurney, D. H., \& Pfaffmann, C. Gustatory adaptation to saliva and sodium chloride. Journal of Experimental Psychology, 1963, 65, 523-529.

McBurney, D. H., \& Shick. T. S. Taste and water taste of 
twenty-six compounds for man. Perception \& Psychophysics, $1971,10,249-252$.

Meiselman, H. L. Adaptation and cross-adaptation of the four gustatory qualities. Perception \& Psychophysics, 1968a, 4, 368-372.

Meiselman, H. L. Magnitude estimations of the course of gustatory adaptation. Perception \& Psychophysics, 1968b, 4, 193-196.

Meiselman, H. L. Effect of presentation procedure on taste intensity functions. Perception \& Psychophysics, 1971, 10, 15-18.

O'Mahony, M. The interstimulus interval for taste: 1. The efficiency of expectoration and mouthrinsing in clearing the mouth of salt residuals. Perception, 1972a, 1, 209-215.

O'Mahony, M. The interstimulus interval for taste: 2. Salt taste sensitivity drifts and the effects on intensity scaling and threshold measurement. Perception, 1972b, 1, 217-222.

O'Mahony, M. Purity effects and distilled water taste. Nature, 1972 c, $240,489$.

O'Mahony, M. Qualitative descriptions of low concentration sodium chloride solutions. British Journal of Psychology, $1973,64,000-000$.

O'Mahony, M. Salt taste sensitivity: A signal detection approach. Perception, in press, a.

O'Mahony. M. A simple flow system for controlled gustatory stimulation avoiding stimulus delay or mixing. Medical \& Biological Engineering, in press, $\mathrm{b}$.

O'Mahony, M., \& Godman, L. Taste descriptions for low concentration $\mathrm{NaCl}$ solutions-use of novel descriptions. IRCS Medical Science, 1973a, June, No. (73-6)39-2-11.

O'Mahony, M., \& Godman, $\mathrm{L}$. $\mathrm{NaCl}$ taste quality descriptions with nine category names provided. IRCS Medical Science, 1973b, June, No. (73-6)39-2-12.

Richter, C. P., \& MacLean, A. Salt taste thresholds of humans. American Journal of Physiology, 1939, 126, 1-6.

Smith, D. V., \& McBurney, D. H. Gustatory cross-adaptation: Does a single mechanism code the salty taste? Journal of Experimental Psychology, 1969, 80, 101-105.

U.S. Department of Agriculture. Experimental procedure for conducting taste and smell tests. U.S. Department of Agriculture, Agricultural Research Administration, mimeographed paper, $1943,16 \mathrm{pp}$.

Williams, R. A. Human detectability thresholds for saccharin, sodium saccharin, and sodium chloride. Journal of Comparative \& Physiological Psychology, 1970, 70, 113-115.

(Received for publication March 23, 1973; revision received May 29, 1973.) 